\title{
Toxicity Analysis in the ADEBAR Trial: Sequential Anthracycline-Taxane Therapy Compared with FEC120 for the Adjuvant Treatment of High-Risk Breast Cancer
}

\author{
Alexandra Schönherr ${ }^{\mathrm{a}}$ Viktoria Aivazova-Fuchs ${ }^{\mathrm{b}}$ Katja Annecke ${ }^{\mathrm{c}}$ Julia Jückstock ${ }^{\mathrm{d}, \mathrm{e}}$ \\ Philip Hepp ${ }^{a}$ Ulrich Andergassen ${ }^{d, e}$ Doris Augustin $^{f}$ Wolfgang Simon $^{g}$ Arthur Wischnik ${ }^{\mathrm{h}}$ \\ Svjetlana Mohrmann $^{a}$ Jessica Salmen ${ }^{a}$ Thomas Zwingers ${ }^{i}$ Marion Kiechle $^{c}$ \\ Nadja Harbeck ${ }^{\mathrm{e}}$ Klaus Friese $^{\mathrm{d}, \mathrm{e}}$ Wolfgang Janni $^{\mathrm{a}}$ Brigitte Rack $^{\mathrm{d}, \mathrm{e}}$

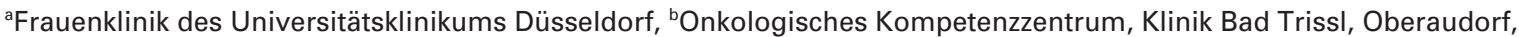 \\ ${ }^{c}$ Frauenklinik und Poliklinik der Technischen Universität München, ${ }^{d}$ Klinik und Poliklinik für Frauenheilkunde und Geburtshilfe,

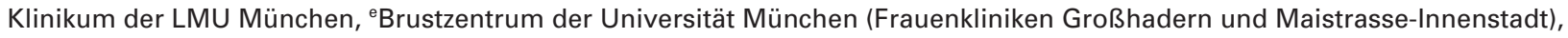 \\ ${ }^{f}$ Frauenklinik, Klinikum Deggendorf, ${ }^{9}$ Abteilung für Frauenheilkunde und Geburtshilfe, Robert Bosch Krankenhaus, Stuttgart,

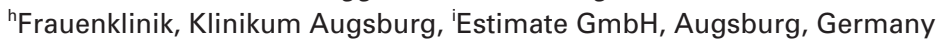

\section{Keywords}

Breast cancer - Taxane - Anthracycline - Toxicity · ADEBAR trial

\section{Summary}

Background: Data from meta-analyses have shown taxane-containing therapies to be superior to anthracycline-based treatments for high-risk breast cancer. Patients and Methods: The ADEBAR trial was a multicenter phase III trial in which patients with lymph nodepositive breast cancer were prospectively randomized for either sequential anthracycline-taxane or FEC120 therapy. Patients received $4 \times$ epirubicin $\left(90 \mathrm{mg} / \mathrm{m}^{2}\right)$ and cyclophosphamide $\left(600 \mathrm{mg} / \mathrm{m}^{2}\right)$ every 3 weeks (q3w), followed by $4 \times$ docetaxel $\left(100 \mathrm{mg} / \mathrm{m}^{2}\right)$ q3w (EC-Doc arm), or $6 \times$ epirubicin $\left(60 \mathrm{mg} / \mathrm{m}^{2}\right)$ and 5 -fluorouracil $\left(500 \mathrm{mg} / \mathrm{m}^{2}\right)$ on days 1 and 8 and cyclophosphamide $\left(75 \mathrm{mg} / \mathrm{m}^{2}\right)$ on days 1-14, q4w (FEC arm). We compared both arms with respect to toxicity and feasibility. Results: Hematological toxicity was found significantly more often in the FEC arm. Febrile neutropenia was seen in $11.3 \%$ of patients in the FEC arm and in $8.4 \%$ of patients in the EC-Doc arm ( $p=0.027$ ). Non-hematological side effects of grade $3 / 4$ were rarely seen in either arm. Therapy was terminated due to toxicity in $3.7 \%$ of the patients in the EC-Doc arm and in $8.0 \%$ of the patients in the FEC arm ( $p=0.0009)$. Conclusion: The sequential anthracycline-taxane regimen is a well-tolerated and feasible alternative to FEC120 therapy.

\author{
Schlüsselwörter \\ Mammakarzinom - Taxan · Anthrazyklin · Toxizität · \\ ADEBAR-Studie
}

\section{Zusammenfassung}

Hintergrund: Metaanalysen zeigten die Überlegenheit von taxanhaltigen Chemotherapien gegenüber rein anthrazyklinbasierten Therapieregimen bei HochrisikoMammakarzinompatientinnen. Patienten und Methode: Die ADEBAR-Studie, als multizentrische Phase-III-Studie, randomisierte nodalpositive Mammakarzinompatientinnen entweder in den sequentiellen AnthrazyklinTaxan-Arm oder in den FEC120-Arm. Die Patientinnen erhielten $4 \times$ Epirubicin $\left(90 \mathrm{mg} / \mathrm{m}^{2}\right)$ und Cyclophosphamid $\left(600 \mathrm{mg} / \mathrm{m}^{2}\right)$ q3w, gefolgt von $4 \times$ Docetaxel $\left(100 \mathrm{mg} / \mathrm{m}^{2}\right)$ q3w (EC-Doc-Arm) oder 6x Epirubicin $\left(60 \mathrm{mg} / \mathrm{m}^{2}\right)$ und 5-Fluorouracil $\left(500 \mathrm{mg} / \mathrm{m}^{2}\right)$ an den Tagen 1 und 8 und Cyclophosphamid $\left(75 \mathrm{mg} / \mathrm{m}^{2}\right)$ an den Tagen 1-14, q4w (FEC-Arm). Wir verglichen beide Arme bezüglich der Toxizitäten. Ergebnisse: Hämatologische Toxizität fand sich signifikant häufiger im FEC-Arm. Febrile Neutropenie trat bei $11,3 \%$ der Patientinnen im FEC-Arm auf sowie bei $8,4 \%$ der Patientinnen im EC-Doc-Arm $(p=0,027)$. Schwere nicht-hämatologische Nebenwirkungen Grad 3/4 traten in beiden Armen selten auf. Aufgrund von Toxizitäten musste die Therapie bei 3,7\% der Patientinnen im EC-Doc-Arm sowie bei 8,0\% der Patientinnen im FEC-Arm abgebrochen werden ( $p=0,0009)$. Schlussfolgerung: Das sequentielle Anthrazyklin-TaxanRegime ist eine gut verträgliche Alternative zu FEC120.

\section{KARGER}

Fax +497614520714

Information@Karger.de

www.karger.com (c) 2012 S. Karger GmbH, Freiburg $1661-3791 / 12 / 0074-0289 \$ 38.00 / 0$ 


\section{Introduction}

Adjuvant chemotherapy reduces the risk of cancer recurrence for patients with high-risk breast cancer [1]. However, the side effects of chemotherapy may cause problems that can even be life threatening. Therefore, it is of great importance to identify effective and well-tolerated chemotherapy regimens. In an effort to prolong disease-free and overall survival, doxorucibin- or epirubicin-based regimens have replaced CMF (cyclophosphamide, methotrexate, fluorouracil) as the standard chemotherapy used in the adjuvant situations [2-5].

The 2 widely-used FEC (fluorouracil, epirubicin, cyclophosphamide) regimens are the dose-dense FEC120 (Levine) (5-fluorouracil $500 \mathrm{mg} / \mathrm{m}^{2} /$ intravenously (i.v.) days $1+8$ every 4 weeks (q4w), epirubicin $60 \mathrm{mg} / \mathrm{m}^{2} /$ i.v. days $1+8 \mathrm{q} 4 \mathrm{w}$ and cyclophosphamide $75 \mathrm{mg} / \mathrm{m}^{2} /$ orally (p.o.) days $1-14 \mathrm{q} 4 \mathrm{w}$ ) and the FEC100 (Boneterre) (5-fluorouracil $500 \mathrm{mg} / \mathrm{m}^{2} /$ i.v. day 1 q3w, epirubicin $100 \mathrm{mg} / \mathrm{m}^{2} /$ i.v. day $1 \mathrm{q} 3 \mathrm{w}$ and cyclophosphamide $500 \mathrm{mg} / \mathrm{m}^{2} /$ i.v. day $1 \mathrm{q} 3 \mathrm{w}$ ) [2, 6]. Commonly observed side effects of FEC chemotherapy are myelosuppression, febrile neutropenia, mucositis, nausea, vomiting and alopecia; each of those can cause great damage to the patients. FEC120 chemotherapy that delivers a cumulative dose of $720 \mathrm{mg}$ epirubicin is thought to be more toxic than FEC100. Although studies comparing FEC100 and FEC120 are not available, cardiotoxicity can be assumed to be a major problem of the higher anthracycline dose.

Taxanes have been added to chemotherapy regimens to improve the efficiency of breast cancer treatment. Initially, in the metastatic setting, they were superior to anthracyclines [7-9]. In the adjuvant situation, meta-analytic data showed a significant increase in disease-free and overall survival rates for patients following taxane therapy, in particular for patients with node-positive breast cancers [10-15]. On the other hand, treatment with the taxane compound docetaxel had shown severe side effects for patients, including neutropenia (76.4\%), anemia (8.9\%), neurological symptoms (4\%), stomatitis $(5.3 \%)$, and dermal affections (5.9\%).

In the present study, we investigated the feasibility of epirubicin-based chemotherapy with or without a taxane by evaluating chemotherapy-induced toxicity in data from the ADEBAR trial.

\section{Patients and Methods}

The ADEBAR trial was a multicenter phase III trial for patients with high-risk breast cancer ( $\geq 4$ involved lymph nodes). The trial primarily served to compare recurrence-free survival rates, and further aims were to compare overall survival, quality of life, and toxicity.

\section{Chemotherapy}

Patients were prospectively randomized into 2 groups. For patients in Arm A (EC-Doc), 4 cycles of epirubicin at $90 \mathrm{mg} / \mathrm{m}^{2}$ and cyclophosphamide at $600 \mathrm{mg} / \mathrm{m}^{2}$ (EC) every 3 weeks (q3w) were followed by 4 cycles of docetaxel at $100 \mathrm{mg} / \mathrm{m}^{2}$ (Doc) q3w. For patients in Arm B $\left(\mathrm{FEC}_{120}\right)$, 6 cycles of epirubicin at $60 \mathrm{mg} / \mathrm{m}^{2}$ and 5 -fluorouracil at $500 \mathrm{mg} / \mathrm{m}^{2}$ i.v. were given on days $1+8$ with cyclophosphamide at $75 \mathrm{mg} / \mathrm{m}^{2}$ p.o. on days $1-14$, q4w.

\section{Co-Medication and Supportive Care}

Patients received co-medication with dexamethasone, mesna (sodium 2-sulfanylethanesulfonate) and 5-HT3 antagonists. According to the study design, granulocyte colony-stimulating factor (G-CSF), erythropoietin and antibiotics were given when required. G-CSF was applied as a secondary prophylaxis in the following cases: febrile neutropenia; neutropenia (absolute neutrophil count $\left.(\mathrm{ANC})<0.5 \times 10^{9} / 1\right)$ lasting more than 5 days; severe neutropenia $\left(\mathrm{ANC}<0.1 \times 10^{9} / 1\right)$; and if an extension of the therapy interval was necessary due to insufficient levels of leukocytes $\left(<3.0 \times 10^{9} / 1\right)$ or neutrophils $\left(\mathrm{ANC}<1.5 \times 10^{9} / 1\right)$. Erythropoietin $(300 \mu \mathrm{g} / \mathrm{q} 2 \mathrm{w}$ or $150 \mu \mathrm{g} / \mathrm{q} 1 \mathrm{w})$ was recommended for chemotherapy-associated anemia $(\leq 11 \mathrm{~g} / \mathrm{dl})$, or if hemoglobin levels decreased more than $3 \mathrm{~g} / \mathrm{dl}$ in 3 months. Prophylactic oral antibiotics were recommended if the levels of neutrophil granulocytes were $<0.5 \times 10^{9} / 1$, regardless of G-CSF application. For febrile neutropenia, hospitalization and i.v. antibiotic therapies were recommended in the study protocol.

\section{Delay and Dose Reduction}

Chemotherapy was delayed for a maximum of 2 weeks in cases of hematological or non-hematological toxicity. A dose reduction by 1 level was performed successively for cases of severe hematological toxicity where secondary prophylactic application of G-CSF was unsuccessful. Nonhematological toxicities of grade 3 or 4 led to either a dose reduction or termination of the therapy. Minor cardiac symptoms, including isolated asymptomatic ventricular extrasystoles, were monitored, and patients were allowed to continue treatment. However, patients were removed from the study when arrhythmias required treatment or there was a significant reduction in left ventricular ejection fraction (LVEF) (Study protocol of the ADEBAR-Trial, Version 3.0, 07/2003, 1).

\section{Data Collection}

Data were collected using online clinical response forms. Data quality was controlled by a clinical research organization (CRO), which visited and monitored the study centers. Therapy-associated toxicity was evaluated using the Common Toxicity Criteria of the NCI (National Cancer Institute), once before each chemotherapy cycle, and once 28 days after the end of chemotherapy. Electrocardiography (ECG) was performed before each chemotherapy cycle and once 28 days after the end of chemotherapy, and echocardiography just before chemotherapy and 6 month after the last cycle or when cardiac symptoms occurred.

\section{Statistical Analysis}

Therapy-associated toxicities were compared using the $\chi^{2}$ test; Fisher's exact test was used for cases of cell frequencies that were less than 5 . A value of $\mathrm{p}<0.05$ was considered significant in 2 -sided tests. No adjustments of the error probability for multiplicity were performed. All analyses were performed using Statistical Analysis Software Version 9.2 (SAS Institute Inc., Cary, NC, USA).

\section{Results}

From 2001 to 2005, 1,496 patients were included into the ADEBAR trial. Of these, 749 were randomly placed in the EC-Doc group, and 747 were placed in the FEC group. Patient and tumor characteristics are shown in table 1. Complete data sets for the evaluation of toxicity were available for 
1,306 patients, including 661 in the EC-Doc group and 645 in the FEC group. The absence of any toxicity was rare and was found in only $0.8 \%$ of patients in the EC-Doc group and in $0.9 \%$ in the FEC group. Toxicity grades of 1 and 2 were equally distributed in the EC-Doc group (13.5\%) and the FEC group (12.9\%). Similarly, toxicity grades of 3 and 4 were found in $85.8 \%$ of patients in the EC-Doc group and in $86.2 \%$ of patients in the FEC group. Severe adverse events (SAEs) were found in $21.3 \%$ of patients in the EC-Doc group and in $28.4 \%$ of patients in the FEC group $(p=0.003)$.

\section{Hematological Toxicity}

Hematological toxicity of grade 3 or 4 (table 2) was found more often in the FEC group. Leukopenia and neutropenia were the most frequent side effects in both groups. There was a highly significant difference $(\mathrm{p}=0.001)$ in the rates of grade $3 / 4$ leukopenia between the groups (72\% EC-Doc and $80 \%$ FEC). Febrile neutropenia, however, occurred significantly more frequently during FEC than during EC-Doc treatment (11.3\% vs. $8.4 \% ; p=0.027)$. The application of $\mathrm{G}-\mathrm{CSF}$ was only necessary in $39.2 \%$ of the EC-Doc patients, whereas G-CSF was given to $61.4 \%$ of the FEC patients ( $p<0.001$ ). More infections occurred in the FEC group (15.5\%) than in the EC-Doc group $(9.4 \%)(\mathrm{p}=0.001)$. Therefore, i.v. antibiotic therapy was necessary more often in the FEC group than in the EC-Doc group (19.7\% vs. $10.4 \%$; p < 0.001). Anemia and thrombocytopenia were rarely found in the ECDoc group, but these conditions were more frequent in the FEC group (anemia $2.8 \%$ vs. $15.5 \%$, thrombocytopenia $2 \%$ vs. $23.9 \%$; $<<0.001$ ). Thus, erythropoietin was given to only $8.7 \%$ of patients in the EC-Doc group compared to $20 \%$ of patients in the FEC group $(\mathrm{p}<0.001)$.

\section{Hematological Toxicity during the Course of EC-Doc Therapy}

Significantly less leukopenia of grades 3 and 4 was found during the application of EC (55.8\%) than during the subsequent application of docetaxel $(76.9 \%)(p<0.001)$. The rates of neutropenia were similar, as $62.5 \%$ of patients receiving EC and $57.9 \%$ of those receiving docetaxel therapy $(p=0.291)$ developed this condition. Although G-CSF was given more often during docetaxel than EC therapy (26.2\% vs. $11.3 \%$; $\mathrm{p}<0.0001$ ), the higher incidence of leukopenia during docetaxel therapy could not be avoided. Anemia rarely occurred during the application of docetaxel (1.5\%), but was found in $7.5 \%$ of patients during the application of EC $(p<0.001)$.

Table 1. Patient and tumor characteristics in the study population

\begin{tabular}{|c|c|c|c|}
\hline & EC-Doc & FEC & All \\
\hline \multicolumn{4}{|l|}{ Age (years) } \\
\hline \multirow[t]{2}{*}{ Median/min.-max. } & $54 / 27-71$ & $55 / 25-71$ & $55 / 25-71$ \\
\hline & $\mathrm{n}(\%)$ & $\mathrm{n}(\%)$ & $\mathrm{n}(\%)$ \\
\hline \multicolumn{4}{|l|}{ Menopausal status } \\
\hline Premenopausal & $250(37.0)$ & $245(37.4)$ & $495(37.2)$ \\
\hline Postmenopausal & 417 (61.7) & $406(62.0)$ & $823(61.8)$ \\
\hline \multicolumn{4}{|c|}{ ECOG performance status } \\
\hline 0 & $524(77.5)$ & $486(74.2)$ & $1010(75.9)$ \\
\hline 1 & $124(18.3)$ & $131(20.0)$ & $255(19.2)$ \\
\hline \multicolumn{4}{|l|}{ Histological subtype } \\
\hline Ductal & $479(70.9)$ & $450(68.7)$ & $929(69.8)$ \\
\hline Lobular & $141(20.9)$ & $138(21.1)$ & $279(21.0)$ \\
\hline Other & $51(7.5)$ & $60(9.2)$ & $111(8.3)$ \\
\hline \multicolumn{4}{|l|}{ Tumor size } \\
\hline $\mathrm{T} 1$ & $193(25.8)$ & $198(26.5)$ & $391(26.1)$ \\
\hline $\mathrm{T} 2$ & $393(52.5)$ & $358(47.9)$ & $751(50.2)$ \\
\hline $\mathrm{T} 3$ & $84(11.2)$ & $81(10.8)$ & $165(11.0)$ \\
\hline $\mathrm{T} 4$ & $57(7.6)$ & $72(9.6)$ & $129(8.6)$ \\
\hline \multicolumn{4}{|c|}{ Number of positive axillary lymph nodes } \\
\hline$\geq 4$ & $458(61.1)$ & $457(61.2)$ & $915(61.2)$ \\
\hline$\geq 10$ & $291(38.9)$ & $290(39.1)$ & $581(38.8)$ \\
\hline \multicolumn{4}{|l|}{ Histological grade } \\
\hline Grade $1+2$ & $342(50.6)$ & $332(50.7)$ & $674(50.6)$ \\
\hline Grade 3 & $292(43.2)$ & $262(40.0)$ & $554(41.6)$ \\
\hline \multicolumn{4}{|l|}{ Hormone receptor status } \\
\hline Positive & $503(74.4)$ & $494(75.4)$ & $1117(74.7)$ \\
\hline Negative & $173(25.6)$ & $161(24.6)$ & $379(25.3)$ \\
\hline
\end{tabular}

EC-Doc $=4 \times$ epirubicin $\left(90 \mathrm{mg} / \mathrm{m}^{2}\right)$ and cyclophosphamide $\left(600 \mathrm{mg} / \mathrm{m}^{2}\right)$ every 3 weeks $(\mathrm{q} 3 \mathrm{w})$, followed by $4 \times$ docetaxel $\left(100 \mathrm{mg} / \mathrm{m}^{2}\right) \mathrm{q} 3 \mathrm{w}$ therapy, $\mathrm{FEC}=6 \times$ epirubicin $\left(60 \mathrm{mg} / \mathrm{m}^{2}\right)$ and 5 -fluorouracil $\left(500 \mathrm{mg} / \mathrm{m}^{2}\right)$ on days 1 and 8 and cyclophosphamide $\left(75 \mathrm{mg} / \mathrm{m}^{2}\right)$ on days $1-14, \mathrm{q} 4 \mathrm{w}$ therapy, $\mathrm{ECOG}=$ Eastern Cooperative Oncology Group. 
Table 2. Hematological toxicity - relative frequency of adverse events

\begin{tabular}{|c|c|c|c|}
\hline & EC-Doc, \% & FEC, \% & $\mathrm{p}$ value \\
\hline Anemia grade $3 / 4$ & 2.8 & 15.5 & $<0.001$ \\
\hline Application of erythropoietin (per cycle) & 8.7 & 20 & $<0.001$ \\
\hline Neutropenia grade $3 / 4$ & 59.1 & 61.1 & 0.5 \\
\hline Leukopenia grade $3 / 4$ & 72.0 & 79.8 & 0.001 \\
\hline Application of G-CSF (per cycles) & 39.2 & 61.4 & $<0.001$ \\
\hline Infections & 9.4 & 15.5 & 0.001 \\
\hline Febrile neutropenia & 8.4 & 11.3 & 0.027 \\
\hline Thrombocytopenia grade $3 / 4$ & 2.0 & 23.9 & $<0.001$ \\
\hline
\end{tabular}

Table 3. Non-hematological toxicity of grades 3 and 4 - relative frequency of adverse events

\begin{tabular}{|c|c|c|c|}
\hline & EC-Doc, $\%$ & FEC, \% & $\mathrm{p}$ value \\
\hline \multicolumn{4}{|l|}{ Elevation of liver enzymes grade $3 / 4$} \\
\hline Bilirubin/transaminases & $1.2 / 1.4$ & $0.3 / 1.9$ & $0.11 / 0.52$ \\
\hline \multicolumn{4}{|l|}{ Gastrointestinal symptoms grade $3 / 4$} \\
\hline Nausea/vomiting & $5.1 / 6.2$ & $4.7 / 2.8$ & $0.7 / 0.003$ \\
\hline Diarrhea & 2.7 & 2.3 & 0.7 \\
\hline Mucositis & 8.9 & 8.7 & 0.9 \\
\hline Cardiac symptoms grade $3 / 4$ & 0.3 & 1.1 & 0.10 \\
\hline Edema & 2.6 & 0.3 & $<0.001$ \\
\hline Neurological symptoms grade $3 / 4$ & 3.9 & 0.3 & $<0.001$ \\
\hline Dermatologic symptoms grade $3 / 4$ & 4.2 & 0.8 & $<0.001$ \\
\hline Allergy grade $3 / 4$ & 0.5 & 0 & 0.25 \\
\hline Fever & 1.1 & 0.8 & 0.8 \\
\hline Pain in general grade $3 / 4$ & 14.2 & 3.6 & $<0.001$ \\
\hline Arthralgia, myalgia grade $3 / 4$ & 12.3 & 1.4 & 0.001 \\
\hline
\end{tabular}

Erythropoietin was administered more often during docetaxel $(4.3 \%)$ than during EC $(1.9 \%)$ therapy $(\mathrm{p}<0.0001)$, although the rate of anemia was higher during EC therapy.

\section{Hematological Toxicity during the Course of FEC}

During the 6 cycles of therapy for the FEC group, anemia grade $3 / 4$ was observed in approximately $15 \%$ of the patients. There was greater use of erythropoietin in this treatment group; it was given to $6.3 \%$ of patients in the first 3 cycles and to $12.7 \%$ during the second 3 cycles $(\mathrm{p}<0.0001)$. We found a similar phenomenon for thrombopenia; there were more grade 3 and 4 events in the second half of FEC therapy $(25.3 \%)$ than in the first half of therapy $(18 \%)(p=0.079)$. During the application of FEC, the percentages of patients with leukopenia and neutropenia remained steady, although there were small decreases from the initial levels of $81.6 \%$ to $79.2 \%(p=0.49)$ in cycles $1-3$ and from $68.4 \%$ to $58.0 \%$ ( $\mathrm{p}=0.013$ ) in cycles $4-6$. This correlated with an increased administration of G-CSF in the second half of FEC (47.4\% vs. $32.1 \%$ in the first half; $\mathrm{p}<0.0001)$.

\section{Non-Hematological Toxicity}

In contrast to hematological toxicities, severe non-hematological toxicities of grades 3 and 4 (table 3) were rarely found.
The most frequently observed event in the EC-Doc group as pain $(14.2 \%)$, especially arthralgia and myalgia (12.3\%), which was seldom found in the FEC group (pain $3.6 \%$ and arthralgia/myalgia $1.4 \% ; \mathrm{p}<0.001)$. There was a significant difference in the frequency of patients who experienced severe vomiting between the EC-Doc (6.2\%) and FEC (2.8\%) groups $(\mathrm{p}=0.003)$. Neurological symptoms of grade 3 or 4 and skin affections occurred almost exclusively in the EC-Doc group (vs. FEC group) with 3.9\% (0.3\%) and 4.2\% of patients $(0.8 \%)$ ( $\mathrm{p}<0.001)$, respectively, having these conditions. This effect was mostly due to the administration of docetaxel in the EC-Doc group. Cardiac impairments according to NCI criteria of grade 3 or 4 were rare, and their frequencies were not statistically different between groups (1.1\% FEC vs. $0.3 \%$ EC-Doc) $(\mathrm{p}=0.1)$. Severe edema was also seldom found, but occurred significantly more often in the EC-Doc group (2.6\%) than in the FEC group $(0.3 \%)$ $(\mathrm{p}<0.001)$.

\section{Dose Reduction, Treatment Delay, Treatment Termination and Death during the Trial}

The full set of chemotherapy cycles outlined in the study protocol was administered to $80.3 \%$ of patients in the EC-Doc group and to $77.1 \%$ of patients in the FEC group $(p=0.16)$. 
Twice as many patients in the FEC group $(8.0 \%)$ as in the EC-Doc group $(3.7 \%)$ terminated their therapy $(p=0.002)$ because of toxicity. The rate of denial was identical in both groups at $4.4 \%$. There was no significant difference in the frequency of treatment termination due to tumor progression between groups (EC-Doc at 0.6\%, FEC at 0.5\%). 6 deaths occurred during the observation period. In the FEC group, 1 death was a result of a lung embolism, 1 resulted from perforated sigmadiverticulitis during leukopenia, and 2 were due to cardiac arrest. In the EC-Doc group, 1 death was caused by tumor progression (cerebral metastasis), and 1 by cardiac arrest. On the assessment by the investigators, these deaths were not thought to have been a result of the therapy.

Dose reduction was rarely used during the application of EC treatment $(0.5 \%)$, but was used in $5 \%$ of patients during the docetaxel treatment cycles, in $3.2 \%$ of patients during the first cycle of FEC, and in $9.3 \%$ during the second cycle of FEC therapy. Dose reduction was more often required during FEC $(12.5 \%)$ than during EC-Doc $(5.5 \%)$ therapy $(p=0.046)$. $12 \%$ of patients receiving EC-Doc therapy and $17.2 \%$ receiving FEC therapy had extended time intervals between cycles $(\mathrm{p}<0.001)$.

\section{Discussion}

Sequential anthracycline-taxane regimens have been reported to show good feasibility $[11,12]$, whereas combined regimens have shown higher rates of hematological toxicity $[9,16]$. For example, in the BCIRG 005 trial, docetaxel in combination with doxorubicin and cyclophosphamide (TAC) was associated with more febrile neutropenia [16]. The PACS 01 trial showed that, although patients had improved disease-free survival and overall survival following sequential taxane therapy (using a slightly different chemotherapy regimen than in the ADEBAR trial with $3 \times$ FEC, followed by $3 \times$ Doc), approximately $11 \%$ of them had febrile neutropenia [12].

As taxane-containing regimens are effective for nodal-positive as well as for nodal-negative patients [15, 17, 18], this analysis of the toxicities resulting from sequential FEC-Doc therapy compared with taxane-free, but dose-dense, FEC120 therapy from the ADEBAR trial is a novel approach for evaluating the feasibility of these 2 treatment options. The treatment arm A (EC-Doc) was chosen in reference to the CALBG-9344 and NSABP-B27 trials [19, 20]. The dose of docetaxel used was selected for its approximate equivalence to the dose of paclitaxel used in the CALBG-9344 trial [19]. The treatment arm B (FEC) was chosen in reference to the Levine protocol. The Levine regimen has been shown to be superior in comparison with CMF therapy in a large randomized study [2]. The treatment duration for this regimen was identical to that of arm A. The toxicity resulting from application of the Levine protocol was high, but was indicative of what would have been expected in a dose-intensified anthra- cycline-based regimen. No existing studies have directly compared FEC120 therapy with FEC100, but it is likely that the FEC120 group would have higher levels of toxicity because of the greater cumulative amount of chemotherapeutic agents.

Hematological toxicity and its complications are the greatest challenge in adjuvant chemotherapy for breast cancer. Our data analysis has shown that hematological toxicity, especially neutropenia, is the main side effect of anthracycline and taxane-based chemotherapy, as also observed in the NSABPB-28 and the PACS-01 trials [10, 12, 21]. We found myelotoxicity to be the most common toxicity of grade $3 / 4$ for both groups. The high rate of neutropenia (approximately 60\%) was managed well with secondary G-CSF treatment. Primary application of G-CSF or pegfilgastrim in other docetaxel regimens could have influenced the comparability of the toxicity data [22]. According to the PACS 01 trial, anemia and thrombocytopenia were not the main complications resulting from taxane-based therapy $[12,21]$, while these complications occurred more often during FEC therapy. Overall, hematological toxicity was seen to be the most frequent side effect in FEC120 therapy. Febrile neutropenia occurred in $11.3 \%$ (FEC) and 8.4\% (EC-Doc) of patients. Similar rates of febrile neutropenia were seen in the sequential anthracycline-taxane arm of the BCIRG 005 trial $(8.3 \%)$ and in the PACS01 trial (11\%) [12]. Overall, the rates of hematological toxicities in the ADEBAR trial are equivalent to those seen in other trials.

Severe non-hematological side effects were mainly associated with taxane therapy. Arthralgia and myalgia (12.3\%) were major complications in the EC-Doc group, but were seldom found in the FEC group $(<4 \%)$. Severe docetaxelassociated neurotoxicity and skin affection were each found in $4 \%$ of patients in the taxane group and in $<1 \%$ of patients in the anthracycline group. Patients with neurological toxicities of an NCI grade $>2$ were removed from the trial. The NSABP-B28 trial found a similar rate of arthralgia and/or myalgia in patients from the taxane arm $(12 \%)$, but a higher rate of neurotoxicity in patients $(15 \%)$ who received paclitaxel [10]. Long-term data regarding neurotoxicity from the ADEBAR trial are not yet available, and need to be the subject of further evaluation.

Anthracycline-associated cardiac impairments seldom occurred during the observation period. Cardiac symptoms according to NCI toxicity score were routinely documented during and directly following chemotherapy. Overall, only $0.3 \%$ of patients in the EC-Doc group and $1.1 \%$ in the FEC group experienced cardiac-associated grade 3 or 4 adverse events. Cardiac toxicity could not be evaluated in the longterm-follow up of ADEBAR patients because no further echocardiographic examinations were performed. Regarding the cardiotoxicity of anthracyclines, the PACS-01 trial found a similar rate of cardiac events at the 5-year follow-up (FECDoc, $0.4 \%$; FEC, $1.3 \%$ ) [12]. The 10-year follow-up in the BCIRG 01 trial found the rate of cardiac problems of grade 
$3 / 4$ to be $2 \%$ in the anthracycline (fluorouracil, doxorubicin and cyclophosphamide, FAC) treatment group [18].

For patients receiving alkylating agents as part of their combination chemotherapy, there is a risk of secondary acute myeloid leukemia. Levine showed that $1.4 \%$ of the breast cancer patients developed a leukemia between 15 and 41 months after FEC. No further cases of leukemia occurred during the 10-year follow-up [23]. Thus, during the actual observation period of the ADEBAR trial, that 2 patients developed leukemia is within the normal range. The incidence of secondary leukemia would most likely be greater in the FEC120 group due to the higher cumulative dose of cyclophosphamide, while the different application form of cyclophosphamide in both arms (i.v. versus p.o.) with the possibility of compliance problems taking cyclophosphamide must be considered.

In summary, taxanes have been shown in various trials to be a feasible treatment option [15, 21, 24]. Pooled data on the side effects from 4 trials (including the ADEBAR trial) demonstrate that taxane-containing chemotherapy is acceptable even for elderly patients [25]. Our evaluation of the toxicity in the ADEBAR trial has confirmed the feasibility of sequential taxane-anthracycline chemotherapy.

\section{Conclusion}

The present analysis of the toxicity data from the ADEBAR trial has shown that hematological toxicity was a frequent side effect of treatment and occurred more often in the FEC120 treatment arm. Severe non-hematologic toxicities were rare and were associated with docetaxel treatment. There were significantly more patients who were removed from therapy due to toxicity in the FEC120 arm than in the EC-Doc arm. Therefore, we conclude that the sequential anthracyclinetaxane regimen is a well-tolerated, feasible therapy, which is suitable for patients with high-risk, node-positive breast cancer.

\section{Acknowledgements}

This study was supported by Amgen, Astrazeneca, Novartis, SanofiAventis and Wilex.

\section{Disclosure Statement}

P. Hepp received remuneration from Chugai and Amgen, J. Salmen from Chugai. N. Harbeck declared a consultant/advisory role at Sanofi-Aventis and research funding from Wilex, T. Zwingers is employed at estimate GmbH. B. Rack received speaker's honoraria and research funding from Sanofi-Aventis, Lilly, Novartis, Astra-Zeneca, and Veridex. A. Schönherr, V. Aivazova-Fuchs, K. Annecke, J. Jückstock, U. Andergassen, D. Augustin, W. Simon, A. Wischnik, S. Mohrmann, M. Kiechle, K. Friese and W. Janni have no conflicts of interest to declare.

\section{References}

$\checkmark 1$ Early Breast Cancer Trialists' Collaborative Group (EBCTCG), Peto R, Davies C, et al.: Comparisons between different polychemotherapy regimens for early breast cancer: meta-analyses of long-term outcome among 100,000 women in 123 randomised trials. Lancet 2012;379:432-444.

2 Levine MN, Bramwell VH, Pritchard KI, et al.: Randomized trial of intensive cyclophosphamide, epirubicin, and fluorouracil chemotherapy compared with cyclophosphamide, methotrexate, and fluorouracil in premenopausal women with nodepositive breast cancer. National Cancer Institute of Canada Clinical Trials Group. J Clin Oncol 1998; 16:2651-2658.

3 Coombes RC, Bliss JM, Wils J, et al.: Adjuvant cyclophosphamide, methotrexate, and fluorouracil versus fluorouracil, epirubicin, and cyclophosphamide chemotherapy in premenopausal women with axillary node-positive operable breast cancer: results of a randomized trial. The International Collaborative Cancer Group. J Clin Oncol 1996;14:35-45.
4 Fisher B, Brown AM, Dimitrov NV, et al.: Two months of doxorubicin-cyclophosphamide with and without interval reinduction therapy compared with 6 months of cyclophosphamide, methotrexate, and fluorouracil in positive-node breast cancer patients with tamoxifen-nonresponsive tumors: Results from the National Surgical Adjuvant Breast and Bowel Project B-15. J Clin Oncol 1990;8:1483-1496.

5 Early Breast Cancer Trialists' Collaborative Group (EBCTCG): Effects of chemotherapy and hormonal therapy for early breast cancer on recurrence and 15-year survival: An overview of the randomised trials. Lancet 2005;365:1687-1717.

6 Bonneterre J, Roche H, Kerbrat P, et al.: Epirubicin increases long-term survival in adjuvant chemotherapy of patients with poor-prognosis, node-positive, early breast cancer: 10 -year followup results of the French Adjuvant Study Group 05 randomized trial. J Clin Oncol 2005;23:2686-2693.

7 Ravdin PM, Burris HA 3rd, Cook G, et al.: Phase II trial of docetaxel in advanced anthracyclineresistant or anthracenedione-resistant breast cancer. J Clin Oncol 1995;13:2879-2885.

-8 Chan S, Friedrichs K, Noel D, et al.: Prospective randomized trial of docetaxel versus doxorubicin in patients with metastatic breast cancer. J Clin Oncol 1999;17:2341-2354.
9 Nabholtz JM, Senn HJ, Bezwoda WR, et al.: Prospective randomized trial of docetaxel versus mitomycin plus vinblastine in patients with metastatic breast cancer progressing despite previous anthracycline-containing chemotherapy. 304 Study Group. J Clin Oncol 1999;17:1413-1424.

10 Mamounas EP, Bryant J, Lembersky B, et al.: Paclitaxel after doxorubicin plus cyclophosphamide as adjuvant chemotherapy for node-positive breast cancer: Results from NSABP B-28. J Clin Oncol 2005;23:3686-3696.

11 Martin M, Rodriguez-Lescure A, Ruiz A, et al.: Randomized phase 3 trial of fluorouracil, epirubicin, and cyclophosphamide alone or followed by Paclitaxel for early breast cancer. J Natl Cancer Inst 2008;100:805-814.

12 Roche H, Fumoleau P, Spielmann M, et al.: Sequential adjuvant epirubicin-based and docetaxel chemotherapy for node-positive breast cancer patients: The FNCLCC PACS 01 Trial. J Clin Oncol 2006;24:5664-5671.

13 Martin M, Pienkowski T, Mackey J, et al.: Adjuvant docetaxel for node-positive breast cancer. N Engl J Med 2005;352:2302-2313.

14 Ferguson T, Wilcken N, Vagg R, et al.: Taxanes for adjuvant treatment of early breast cancer. Cochrane Database Syst Rev 2007;CD004421. 
15 Bria E, Nistico C, Cuppone F, et al.: Benefit of taxanes as adjuvant chemotherapy for early breast cancer: Pooled analysis of 15,500 patients. Cancer 2006;106:2337-2344.

16 Eiermann W, Pienkowski T, Crown J, et al.: Phase III study of doxorubicin/cyclophosphamide with concomitant versus sequential docetaxel as adjuvant treatment in patients with human epidermal growth factor receptor 2-normal, node-positive breast cancer: BCIRG-005 trial. J Clin Oncol. 2011; 29:3877-3884.

17 Martin M, Segui MA, Anton A, et al.: Adjuvant docetaxel for high-risk, node-negative breast cancer. N Engl J Med 2010;363:2200-2210.

18 Martin M, Mackey J, Pienkowski T, et al.: Tenyear follow-up analysis of the BCIRG 001 trial confirms superior DFS and OS benefit of adjuvant TAC (docetaxel, doxorubicin, cyclophosphamide) over FAC (fluorouracil, doxorubicin, cyclophosphamide) in women with operable node-positive breast cancer. Cancer Res 2010;70(24 suppl):S4.
Henderson IC, Berry DA, Demetri GD, et al.: Improved outcomes from adding sequential Paclitaxel but not from escalating Doxorubicin dose in an adjuvant chemotherapy regimen for patients with node-positive primary breast cancer. J Clin Oncol 2003;21:976-983.

20 Mamounas EP: NSABP Protocol B-27. Preoperative doxorubicin plus cyclophosphamide followed by preoperative or postoperative docetaxel. Oncology (Williston Park) 1997;11(Suppl 6):37-40.

21 Polyzos A, Malamos N, Boukovinas I, et al.: FEC versus sequential docetaxel followed by epirubicin/cyclophosphamide as adjuvant chemotherapy in women with axillary node-positive early breast cancer: A randomized study of the Hellenic Oncology Research Group (HORG). Breast Cancer Res Treat 2010;119:95-104.

22 Martin M, Lluch A, Segui MA, et al.: Toxicity and health-related quality of life in breast cancer patients receiving adjuvant docetaxel, doxorubicin, cyclophosphamide (TAC) or 5-fluorouracil, doxorubicin and cyclophosphamide (FAC): impact of adding primary prophylactic granulocyte-colony stimulating factor to the TAC regimen. Ann Oncol 2006;17:1205-1212.
23 Levine MN, Pritchard KI, Bramwell VH, et al. Randomized trial comparing cyclophosphamide, epirubicin, and fluorouracil with cyclophosphamide, methotrexate, and fluorouracil in premenopausal women with node-positive breast cancer: update of National Cancer Institute of Canada Clinical Trials Group Trial MA5. J Clin Oncol 2005;23:5166-170.

24 Hirano A, Shimizu T, Watanabe O, et al.: Epirubicin and cyclophosphamide followed by docetaxel as primary systemic chemotherapy in locally advanced breast cancer. Anticancer Res 2008; 8:4137-4142

25 Loibl S, von Minckwitz G, Harbeck N, et al. Clinical feasibility of (neo)adjuvant taxane-based chemotherapy in older patients: Analysis of $>4,500$ patients from four German randomized breast cancer trials. Breast Cancer Res 2008;10:R77. 